\title{
Review of research in cargo transportation reliability
}

\author{
Evgenia Prokofieva ${ }^{1, *}$ \\ ${ }^{1}$ Russian University of Transport, 127994, Obraztsova 9-9, Moscow, Russia
}

\begin{abstract}
The paper contains a review of studies in cargo and empty cars delivery reliability, describes methods of reliability calculation and monetary evaluation. The analysis showed that monetary evaluation when reliability is considered the main emphasis should be put on its for all participants of transportation process. Consignors/consignees are, as a rule, concerned about logistical control in terms of steady and regular carriages; carriers pay more attention to process operations and loading of the infrastructure elements; railway rolling stock operators give the first place to the turnaround of main operating assets.
\end{abstract}

\section{Introduction}

Effective planning of freight transportation is a key element in the transportation process management system and a guarantee for a sustainable financial activity of transport companies. Effective planning is based on the ability to timely determine the transportation demands and needs of different sectors of economy, as well as to analyze their response to any change in the strategy of transportation planning and management. Transportation process stakeholders have to constantly adapt to changes in the transport system (business environment, loading structure, directions of car traffic, etc.) by switching the train destinations, selecting the points of departure/destination, changing the transportation type and time. All this is crucial for implementing a balanced policy in freight transport.

In the context of developing and complicating intra-service relations, reliability is one of the key indicators showing how efficient the business activities of transport companies are. Reliability is particularly important in planning, managing, monitoring, dispatching and rendering freight services [1]. It is well-proven that reliability is the central factor shippers rely on when choosing the means of cargo transportation [2-5]. According to a survey of transport service users conducted by the RAND Corporation, reliability is "a key attribute for choosing the adequate method of conveyance, often even more important than speed" [6].

\section{Defining the problem}

The root cause of failure to provide reliable freight traffic is lack of infrastructure resources (carriage and traffic capacity, operational difficulties caused by infrastructure repairs or

\footnotetext{
${ }^{*}$ Corresponding author: eskolesnikova@mail.ru
} 
consignees not accepting the cargo, etc.). Reliability, as the quality characteristic of performance, is never free of charge. Modern approaches to assessing transport reliability include the assessment of reliability change in percentage terms and cost estimate of the change [7-9].

Researchers in many countries [3, 7, 8, 10-12] propose methods for economic evaluation of the goods delivery reliability. Delays and uncertainty in freight transportation cause an increase in "reserve" stocks and operational costs along with deterioration of competitive ability of enterprises and appreciation of goods for ultimate customers in the long run.

Although assessing freight reliability is important, most world studies prefer assessing passenger transportation. There are only a few papers describing assessment of goods delivery reliability by the key transportation process stakeholders as the key aspect. However, there is no consensus regarding how high the level of reliability should be [13]. Reliability assessment is perhaps one of the most underinvestigated issues in freight transport studies $[14,15]$.

\section{Value of reliability - methods of determining}

The existing studies assess the reliability of cargo delivery based on one of the four indicators below [16]:

- a standard deviation;

- quantiles and percentage points of distribution;

- delayed shipments percent;

- average delay.

Currently, in the context of tough competition, many companies have to plan production "just in time" and cut costs associated with products being kept in the "reserve" stocks. In such circumstances, a reliable transport system is required to enable readily available cargo delivery [9]. Thus, reliability can be determined through the delivery time distribution function and the form of the distribution $[17,18]$.

To make cargo delivery reliable, it is necessary to measure deviations from planned (expected) delivery time, which may be assessed based on actual statistics on carriages performed or external sources (i.e. online sources). Poor compliance with carriage terms may lead to delayed delivery and breach of contractual obligations, which adversely affects the financial performance of enterprises. Since logistic solutions in freight services affect all transportation process stakeholders (i.e. shippers/consignees, rolling stock operators and carriers), delivery reliability effect is a composite function [19].

To retain the competitive advantage, shippers mainly use different strategies sensitive to change in time and cost, such as delivery "just in time", planning of pull and push production processes, to plan their activities. However, success of those strategies largely depends on supply chain reliability. On the other hand, carriers may also benefit from improved delivery reliability, because this would make it possible to cut costs contingent on traffic volume, consolidate conveyance and apply principles of unified end-to-end planning by all transportation stakeholders. A high reliability allows consignors/shippers to avoid excessive spending for keeping "reserve" stocks, additional labor costs, reduce the risks of product supply default and loss of clients [20]. Higher reliability will enable rolling stock operators to increase the working capital turnover (reduction in car turn around), reduce the risks of less revenue and penalties for empty car supply default.

Consequently, consignors, rolling stock operators and carriers make cost estimates differently with regard to the reliability of goods and empty cars delivery. As a result, to analyze preferences for selecting a method of freight transport, all transportation process stakeholder shall be taken into account. Most of the existing studies either focus on one 
type of users (i.e. shippers and carriers), or ignore differences between groups, maybe because of lack of reliable data. The differences between the groups were investigated only in a few papers $[1,3,21]$.

The vast majority of studies use "timely delivery" as an indicator for measuring reliability for the whole transport network. This indicator has become common practice because it is widely practiced by decision-makers in freight transport [5]. It measures reliability as percent of shipped cargoes delivered within the scheduled transportation time, and can be expressed by probability:

$$
R=P_{r}\left(T \leq T_{p}\right)
$$

where $R$ - is the transport network reliability; $T$ - is the actual transportation time (cargo delivery term); $T_{p}$ - is the planned transport time (cargo delivery term).

The proposed method allows evaluating a change in the delivery time reliability. The basis for it is the probabilistic method of first-order second-moment (FOSM) for determining stochastic moments of functions with random input variables. The method is used to aggregate levels of reliability. In engineering, FOSM algorithm is widely used to calculate reliability of system performance, and described with the help of the function of statistically independent random variables [22]:

$$
g(X)=g\left(X_{1}, X_{2}, \ldots \ldots, X_{n}\right)
$$

where $X-$ is the vector describing elements of the system; $X_{i}(i=1,2,3 \ldots . n)-$ are elements of the system.

Monetary evaluation of reliability is a monetary cost that users are ready to pay in order to increase delivery reliability when goods are conveyed from a manufacturing site to points of consumption. To monetarily evaluate freight transport reliability, the existing studies most often used two approaches: method of random utility maximization (RUM) and the inventory count method [9]. RUM approach considers a risky behavior of freight service consumers and uncertain time of transportation completion (actual cargo delivery term), and makes reliability cost estimate based on utility maximization for the user by defining a compromise between reliability and cost $[2,9,19$, etc. $]$.

The method based on inventory count uses a slightly different approach to take into account both decisions on transportation method and stock management. The said method assumes that a timely delivery is closely linked to stock management decisions. For example, the authors [23] have modeled levels of "reserve" production stocks for various methods of transporting goods in due time. Such an assessment of "reserve" stocks for different levels of uncertainty made it possible to determine the quantity of products to be stored in the warehouse. These amounts were quantitatively represented in monetary terms by multiplying the value of goods and cost of their storage, and thus they reflected the cost estimate suitable for a company to pay for different levels of service. This approach allows evaluation of overall savings to avoid any uncertainty.

In addition to methods based on random utility maximization and determination of "reserve" stocks, a separate group of authors applied the approach of profit maximization or cost minimization [24]. This approach uses the cost function, where all attributes (including the number of shippers, delivery time of goods, delivery reliability, characteristics of the company and characteristics of shipment) are converted into a generalized cost:

$$
\pi(p, w, Z, S)=\operatorname{Max}_{l}(l, Z, S)-T C(Z, S)
$$

where $\pi$ - is a profit; $p$ - the cost (price) of products; $w$ - operating cost vector; $l$ operational factor vector (labor cost and capital); $Z$ - characteristics directly related to 
transportation (such as reliability, etc.); and $S$ - the characteristics of an individual company.

With that in mind, a user is trying to minimize costs or maximize profits, given the constraints. The basic assumption is that the user is likely to choose the option with the lowest cost transportation. Having found the profit differential between the two alternatives, one can estimate the marginal replacement rate between the transport characteristics, $Z$ (such as reliability) and profit (monetary value that the company is ready to pay).

\section{Data and discussion}

Regulations of JSC "Russian Railways" define reliability of cargo and empty cars delivery by the specified time is defined as being a share of shipped cargoes that have arrived without delays $[25,26]$ :

$$
H_{D(i j)}=P\left(x<D_{\mathrm{H}(i j)}\right)=\Phi^{*}\left[\frac{3\left(D_{\mathrm{H}(i j)}-D_{\mathrm{T}(i j)}\right)}{D_{\mathrm{T}(i j)}-\min D_{\mathrm{T}(i j)}}\right]
$$

where $x$ - is the actual delivery term, days; $\Phi^{*}-$ is the normal distribution function; $D_{H}(i j)$ - is the standard delivery term, days, in accordance with Rules for Calculating the Terms of Cargo Delivery by Rail; $D_{T}(i j)$ - is the technological delivery term, days, in accordance with the established procedure of car traffic direction and marshalling.

The analysis of statistical reports by JSC "Russian Railways" shows a positive trend in speed and delivery reliability growth along with improvement in transportation management quality (Fig. 1, 2).

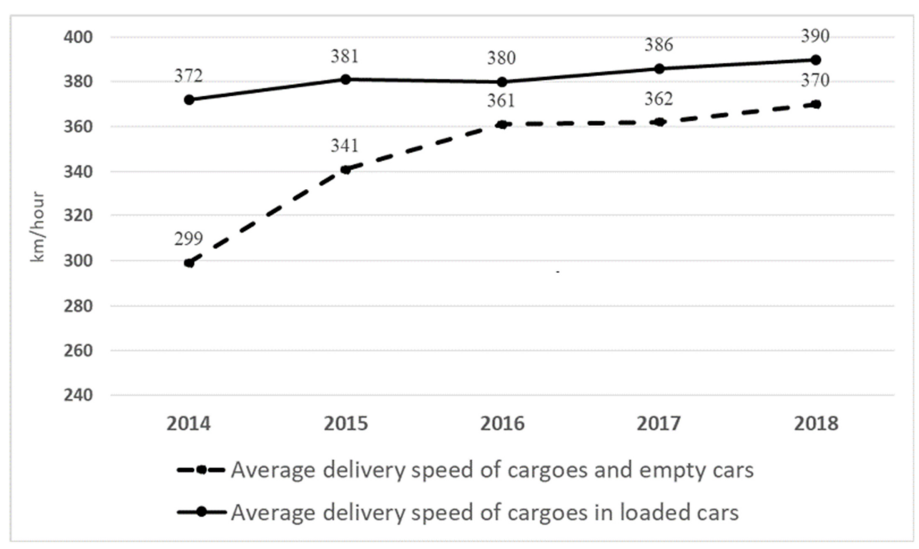

Fig. 1. Average speed dynamics of cargoes delivered in 2014-2018. 


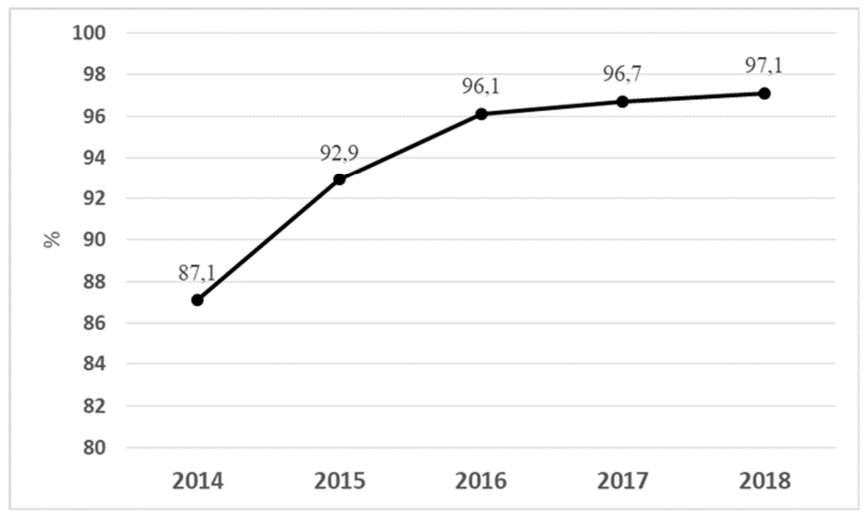

Fig. 2. Reliability dynamics of cargo and empty car delivery in 2014-2018.

Reliability of cargo and empty car delivery grew up to $97.1 \%$ in 2018 . At that time, the average delivery speed was $376.4 \mathrm{~km}$ per day. It increased by $8 \mathrm{~km}$ as compared with the previous year. Delivery speed of cargo loaded in cars made up $390 \mathrm{~km} /$ day with a $4 \mathrm{~km}$ increase. The analysis has shown that about $70 \%$ of all in-transit stoppages that cause delays are due to consignors/consignees. The analysis testifies improved quality of transport services rendered to cargo interests.

\section{Conclusions}

The analysis showed that monetary evaluation when reliability is considered the main emphasis should be put on its for all participants of transportation process. Consignors/consignees are, as a rule, concerned about logistical control in terms of steady and regular carriages; carriers pay more attention to process operations and loading of the infrastructure elements; railway rolling stock operators give the first place to the turnaround of main operating assets.

It can be said that, despite the progress achieved in economic model and design, results of these investigations are of limited application. This is largely due to the fact that the studies under review use different units to determine reliability, which makes the results difficult to compare. Consequently, there is no consensus about a recommended level of reliability and its monetary evaluation in freight transportation.

\section{References}

1. A. S. Fowkes, P. E. Firmin, G. Tweddle, A. E. Whiteing, International Journal of Logistics 7(1), 33-43 (2004). DOI: 10.1080/13675560310001619259

2. C. Winston, Econometrica 49(4), 981-1006 (1981).

3. G. De Jong, M. Kouwenhoven, J. Bates, P. Koster, E. Verhoef, L. Tavasszy, et al. Logistics and Transportation Review 64, 71-87 (2014). DOI:10.1016/j.tre.2014.01.008

4. V. Reis, Transportation Research Part A 61(3), 100-120 (2014). DOI:10.1016/j.tra.2014.01.002

5. K. Shams, H. Asgari, X. Jin, Transportation Research Part A: Policy and Practice 102, 228-243 (2014). DOI:10.1016/j.tra.2016.08.001 
6. R. Hillestad, B.D. Van Roo, K.D. Yoho, Fast-Forward: Key Issues in Modernizing the US Freight-Transportation System for Future Economic Growth (Rand Corporation, 2009). DOI:10.7249/MG883

7. R. Eddington, The eddington transport study: Main report London (UK: HM Treasury, 2006).

8. A. H. Halse, H. Samstad, M. Killi, S. Flügel, F. Ramjerdi, Valuation of freight transport time and reliability (TOI report 1083/2010, Oslo, Norway, 2010).

9. A. Nicholson, Research in Transportation Economics 49, 14-21 (2015). DOI:10.1016/j.retrec.2015.04.002

10. N. A. Krüger, I. Vierth, European Transport Research Review 7(1), 6-15 (2015). DOI:10.1007/s12544-015-0155-7.

11. D. A. Hensher, S. M. Puckett, J. M. Rose, Transportation Research Part B: Methodological 41(9), 924-949 (2007). DOI:10.1016/j.trb.2007.04.003

12. N. Z. Transfund, Project evaluation manual (Wellington, NZ: Transfund NZ, 2004).

13. L. Zamparini, A. Reggiani, The value of reliability and its relevance in transport networks. Integrated Transport: From Policy to Practice, 97-115 (2019).

14. V. Gatta, E. Marcucci, Transport Policy 36, 248-252 (2014). DOI:10.1016/j.tranpol.2014.09.007

15. D. Hensher, M.A. Figliozzi, Transportation Research Part B: Methodological 41(9), 921-923 (2007). DOI:10.1016/j.trb.2007.04.002

16. M. Andersson, M. Berglund, J. Flodén, C. Persson, J. Waidringer, Research in Transportation Economics 66, 59-69 (2017). DOI:10.1016/j.retrec.2017.03.001

17. M. G. H. Bell, C. Cassir, Reliability of transport networks (London, UK: Research Studies Press, 2000).

18. J. W. C. V. Van Lint, H. J. V. Zuylen, H. Tu, Transportation Research Part A 42(1), 258-277 (2008). DOI:10.1016/j.tra.2007.08.008

19. K.A. Small, Transportation Research 431 (1999).

20. A. McKinnon, The Impact of Traffic Congestion on Logistical Efficiency (Heriot-Watt University, Edinburgh, 1998).

21. A. Halse, H. Samstad, M. Killi, S. Flugel, F. Ramjerdi, Value of Freight Transport Time and Reliability (Institute of Transport Economics, 2010).

22. A. M. Hasofer, N. C. Lind, Journal of the Engineering Mechanics Division 100(1), 111-121 (1974).

23. W. Dullaert, L. Zamparini, Transportation Research Part E: Logistic Transportation Review 49, 190-200 (2013). DOI:10.1016/j.tre.2012.08.005

24. E. Bergkvist, Freight Transportation: Valuation of Time and Forecasting of Flows (Umea University, Sweden, 2001).

25. Methods for calculating performance indicators of car parks that allow monitoring, analysis and evaluation of the impact of redundancy of parks on the efficiency and effectiveness of the network (JSC "Russian Railways", 2015).

26. Approval of the Methodology for evaluating and criteria for economic efficiency of sending routes (JSC "Russian Railways", 2017). 